\title{
'Naaman's dilemma'-factors influencing the compliance of patients to prescribed drugs in chronic diseases, with particular reference to leprosy
}

\author{
R MACRORIE \\ Green College, Woodstock Road, Oxford, England
}

\begin{abstract}
"And Elisha sent a messenger unto him, saying "Go and wash in Jordan seven times, and thy flesh shall come again to thee, and thou shalt be clean". But Naaman was wroth, and went away, and said "Behold, I thought, he will surely come out to me, and stand, and call on the name of the Lord his God, and strike his hand over the place, and recover the leper. Are not Abana and Pharpar, rivers of Damascus, better than all the waters of Israel? May I not wash in them and be clean?" So he turned and went away in a rage."

The history of therapeutics is that of a n accelerating change from the management of tradition to the management of fashion. Historical investigation of traditional attitudes to treatment ${ }^{2.3}$ helps explain patient expectations and rejection of modern powerful drugs. Some themes common to most cultures include:
\end{abstract}

All treatment modes are useful, including diet, hygiene, quarantine, and psychotherapy. Today this is more successfully exploited by traditional medical systems, such as the Indian Ayurvedic which advises leprosy patients on physical activity and sexual indulgence. ${ }^{4} \mathrm{~A}$ patient given only a bottle of pills may justly feel dissatisfied.

2 A religious element has always been emphasized, in which diagnosis, prognosis and treatment are not distinguished. Modern dispensing may not leave room for the community priest, or even consistent personal care.

3 Participation is the rule, with treatment procedures, of the individual, his family and friends and of local community leaders. The advantages of this involvement for promoting compliance are only slowly being rediscovered.

4 The basis for treatment does not require scientific justification, but rather tradition and intuition. This conservative outlook contrasts sharply with the modern turnover of proposed therapies.

5 Drugs have never been free. If, in theory, free treatment would seem to encourage open access to services, often in practice the bought medicine is better respected and used correctly.

6 Drugs are not necessarily simple in formula nor free of unpleasant side-effects. These are 2 priority problems according to modern therapeutics, but in good hands such drugs may be more trusted and accepted for their potency.

* This essay is an abridged version of one of the prize-winning entries for 1983 in a yearly essay competition, organized by LEPRA and offered to undergraduates in all the medical schools of the UK. Prize-winning essays for previous years have been published in this Journal and in the International Journal of Leprosy. EDITOR 
As the problems of efficacy and availability have been croded, the problem of compliance has been increasingly exposed. ${ }^{5}$ The carly momentum of steadily reducing incidence of leprosy now appears to be lost, ${ }^{6}$ while pharmacological barriers have been superseded by social and economical ones.

\section{A Definition of the problem}

The difficulties in making an effective response to the compliance problem begin with an uncertainty about the aims of treatment and a confusion between population and individual aims.

\section{(i) POPULATION AIMS}

To effectively and rapidly diminish the infectivity of the host. ${ }^{7}$ This places priority in case-finding for the more infectious, but less prevalent lepromatous form, ${ }^{8}$ and in regimen for the rapidly bactericidal agents such as rifampicin. ${ }^{9}$

2 To rehabilitate the patient into his former home and employment. This implies making drugs available at workplaces and communal domestic facilities, and increasing cost-effective orthopaedic and occupational therapy facilities.

\section{(ii) INDIVIDUAL AIMS}

To achieve a satisfactory symptomatic outcome. This requires a drug treatment with minimal side-effects and a rapid response to reversal reactions. Results ought not to be based solely on negative smears, but on systematic evaluation of outcome using, for example, the Brook indices: ${ }^{10}$

(a) Symptom status - related to the major reason for referral.

(b) Activity status - related to the tasks demanded at work.

(c) Ambulatory status - based on the ability to walk an arbitrary distance.

2 To maintain a good doctor-patient relationship and a positive attitude to maintaining health. This becomes the priority after the initial recovery period, and requires a holistic concern for the patient, and very different compliance motivators. The particular challenge for leprosy treatment is aptly summed up by Graham Greene:

"a patient can always detect whether he is loved or whether it is only his leprosy which is loved'."

\section{B Extent of the problem}

Patients have rejected treatments for as long as they have been proposed, though modern doctors have forgotten Hippocrates' warning that the physician 'should keep aware of the fact that patients often lie when they state that they have taken certain medicines'. ${ }^{2}$ Non-compliance with self-administration of dapsone in leprosy was also long appreciated. Ross-Innes observed that outpatient treatment could rarely be relied upon, and saw the need for a depot injectable form of dapsone for supervised treatment. ${ }^{13}$

Objective surveys of outpatient compliance in leprosy were delayed by the peculiar difficulties of direct urine testing for dapsone as a measure of drug ingestion; specifically, the long half-life and diuresis-dependent excretion of the drug. This was partially solved by Ellard et al. ${ }^{14}$ using the dapsone:creatinine ratio. This still requires consecutive samples, or a suitably supervised control population, to interpret the results, but has been used by many workers in subsequent surveys (see Table 1). 


\section{Definition of compliance}

Compliance is 'action in accordance with a request, command, etc.' (Shorter Oxford Dictionary), and summarizes a complex behaviour pattern which may be usefully divided into three to appreciate different requirements in different situations: (i) unawareness - the mistaken action due to the failure of communication of the necessary instructions - a lack of instruction; (ii) error-the mistaken action due to misinformation, misinterpretation or memory failure - a lack of reinforcement; and (iii) Non-conformance - the mistaken action due to the voluntary conscious response of the individual to behavioural advice - a lack of faith.

Compliance is not an entity, but a chain of events, and problems can arise at any stage within it (Figure 1).

The initial hypothesis for a compliance study must identify one such factor. There may be no close correlation between patient attendance at clinics and regular consumption of drugs, ${ }^{13}$ - this is only the case if treatment is administered there and then. ${ }^{20}$

Table 1. Typical figures for non-compliance in dapsone treatment

\begin{tabular}{|c|c|c|c|c|}
\hline Study & Location & Sample & Test & Non compliance rate \\
\hline Hertroijs $(1974)^{15}$ & Tanzania & $5734 \mathrm{O} / \mathrm{P} ’ \mathrm{~S}$ & $\begin{array}{l}\text { Records \& } \\
\text { Interviews }\end{array}$ & $32 \%$ (attendance) \\
\hline Low \& Pearson $(1974)^{16}$ & Ethiopia & 89 O/P'S & $\begin{array}{l}\text { Urine } \\
\mathrm{D}: \mathrm{C} \text { ratio }\end{array}$ & $44 \%$ \\
\hline Ellard et al $(1974)^{17}$ & Malaŵi & 206 O/P'S & $\mathrm{D}:$ C ratio & $49^{\circ} \%$ \\
\hline Hagan et al $(1979)^{18}$ & Burma & 585 O/P'S, 138 I/P'S & $\mathrm{D}: \mathrm{C}$ ratio & $58 \%, 8 \%$ \\
\hline Ellard et al $(1981)^{19}$ & Ethiopia & 295 D/P'S & $\mathrm{D}:$ C ratio & \\
\hline
\end{tabular}

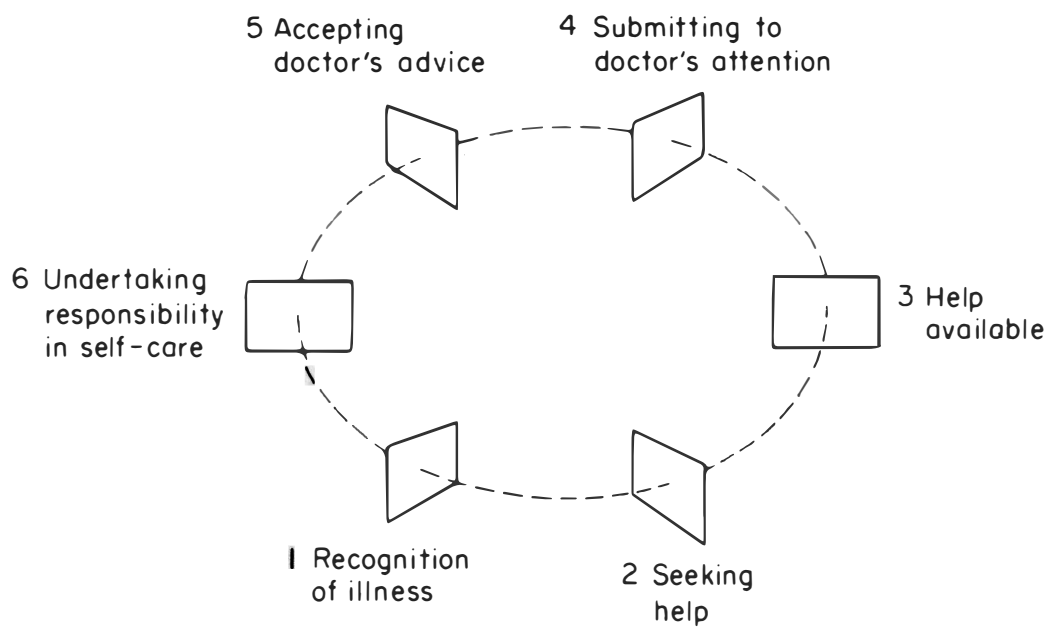

Figure 1. The hurdles of compliance. The patient must keep lapping to persist in therapy. 


\section{Design of compliance surveys}

For results to be interpretable to other clinicians and applicable to clinical conditions, it is essential to be specific and explicit about our interpretation of 'compliance', defining the patients and treatments involved. ${ }^{21}$

(i) Defining patients - The sample must be representative (e.g. referral hospital vs peripheral clinic) and followed through ${ }^{22}$ (i.e. using an inception cohort of patients, following up defaulters at home, etc.).

(ii) Defining treatment-The disease criteria ought to be defined from the start, and the means of dispensing described, as well-planned organizational methods may be more significant than the variables tested. ${ }^{20}$

(iii) Criterion used for compliance-A measurable index for patient compliance is by definition an oversimplification of behaviour, dependent on complex social, medical and personal problems, ${ }^{23}$ and must be interpreted in that context:

The 'ideal' index for compliance rapidly performed and interpreted, quantifiable for comparisons, related to 'therapeutic threshold', closely linked to perceived compliance problems, suitable for mass-testing and longitudinal studies, comparable with other studies, cost-effective within treatment programmes, acceptable to the patient.

Just as the measure used must be related to the appropriate 'hurdle of compliance' so the test result must be related to a pre-determined therapeutic goal, depending on treatment effectiveness and public health strategy. ' $100 \%$ treatment compliance' is neither desirable nor necessary. The costs of tests may be prohibitive in some circumstances, but must be compared with the potential cost of wasted drugs and retreatment. Common methods are shown in Table 2.

Combinations of these methods are often used. Important questions that must be asked of any proposed method are: (i) who does the test? (doctor, health worker, patient, independent investigator); (ii) with whom are you involved? (patient, relative, local figure, doctor); (iii) where do you perform the test? (clinic, home, workplace); and (iv) is the patient aware of the purpose of the test? (before, after performed).

\section{E Factors influencing compliance}

The great thrust of early compliance research was the attempt to find demographical variables which would predict the non-compliant patient. The failure of such indicators to identify problem patients ${ }^{31}$ suggests that the search for the 'non-compliant personality' should be abandoned, to concentrate more on specific patient-treatment problems and the patients' perceived difficulties.

An important factor in interpreting any results is the 'surveillance effect', the fact that experimental conditions themselves influence compliance greatly, by patient selection, doctor motivation, stricter follow-up efforts etc.

\section{(i) MEDICAL FACTORS}

Chronic diseases are protracted, usually non-lethal, intermittently severe in natural history, and require chronic treatment. The patient may respond to this in two ways, depending on treatment effectiveness. If palliative, it might make him bored and disillusioned; if relieving, it might make him complacent and irregular. In leprosy, the apparent mildness of its benign onset as a small macule, and the incidence of spontaneous healing in children, may discourage presentation to a doctor. ${ }^{9 .} 33$ Though polypharmacy of any kind makes compliance difficult, ${ }^{34}$ combination therapy is essential in 
Table 2. Criteria used for compliance

\begin{tabular}{|c|c|c|c|}
\hline Variable & Measure & Advantages & Disadvantages \\
\hline Clinical judgement & 'Intuition’ & $\begin{array}{l}\text { Nearest the goal } \\
\text { Part of clinical practice }\end{array}$ & Proven inaccurate. ${ }^{24 .} 25$ \\
\hline Outcome & e.g. smear activity & Part of clinical practice & $\begin{array}{l}\text { Misses spontaneous } \\
\text { recovery. } \\
\text { Drug resistance }\end{array}$ \\
\hline Pill count & e.g. discrepancy estimate ${ }^{28}$ & $\begin{array}{l}\text { Simple } \\
\text { Useful adjunct }\end{array}$ & $\begin{array}{l}\text { Ignores drugs returned, } \\
\text { given away, discarded } \\
\text { and hoarded. }\end{array}$ \\
\hline Urine testing & $\begin{array}{l}\text { e.g. urine dapsone: } \\
\text { creatinine } \\
\text { - } \text { ratio }^{17} \text { INH label }\end{array}$ & $\begin{array}{l}\text { Cheap } \\
\text { Practical for any drug } \\
\text { objective }\end{array}$ & $\begin{array}{l}\text { Pharmacokinetics- } \\
\text { dependent. } \\
\text { Cross-reactions. } \\
\text { Fraudulent samples. }\end{array}$ \\
\hline Blood testing & e.g. ELISA assay ${ }^{27}$ & Closer to drug use & $\begin{array}{l}\text { Kinetics-dependent still. } \\
\text { Poor patient acceptability. }\end{array}$ \\
\hline Interview & & $\begin{array}{l}\text { Essential for behavioural } \\
\text { study and planning } \\
\text { interventions }\end{array}$ & $\begin{array}{l}\text { Grossly underestimating. } \\
\text { Time consuming. }\end{array}$ \\
\hline Monitors & $\begin{array}{l}\text { e.g. Moulding's } \\
\text { medication monitor }{ }^{29}\end{array}$ & $\begin{array}{l}\text { Objective } \\
\text { Records behaviour } \\
\text { pattern }\end{array}$ & $\begin{array}{l}\text { Not }=\text { ingestion. } \\
\text { Supervision bias costly } \\
\text { ? too frightening }{ }^{30}\end{array}$ \\
\hline
\end{tabular}

the age of antibiotic resistance (Table 3) and must be well-designed to avoid drug-drug interactions'. ${ }^{34}$

Side-effects, such as leprous reversal reactions, ${ }^{35}$ drug sensitivities and neuropathy, are generally well-tolerated. On the other hand, a subjectively obvious effect of treatment is important to avoid Volpone's attitude 'No, no, no, I'm very well, you need prescribe no more'.$^{36}$ The addition of simple topical preparations, such as the obsolete erisul ointment ${ }^{37}$ rubbed into the affected skin, would increase patient satisfaction in a disease treatment sadly lacking this element.

\section{(ii) PERSONAL FACTORS}

Although personality types do not correlate with non-conformance, analyses of patients' attitudes, such as the "health belief model', ${ }^{38}$ provide clues towards explaining health behaviour. Examination of the doctor-patient relationship, such as by recording and analysing clinical interviews, ${ }^{39}$ suggest defects of technique which can be modified by the clinician. Cost of drugs may not be a major obstacle ${ }^{40}$ but use of expensive alternative traditional remedies must be taken into account. Educative measures are an important, but not exclusive, priority in the prescribing interaction. ${ }^{41}$

\section{(iii) SOCIAL FACTORS}

An analysis of cultural and economic factors, which profoundly influence the patient's (and doctor's) behaviour, explain the process of turning vague symptoms into a significant illness. ${ }^{42}$ This defines the illness in terms of 'how disabling is it?' and even 'who is to blame?', which varies for leprosy in different cultures. ${ }^{37}$ Non-conformance may depend more on the extent of disability (i.e. 
Table 3. WHO-recommended treatment protocols $(1982)^{9}$

\begin{tabular}{lll}
\hline & \multicolumn{1}{c}{$\begin{array}{c}\text { Paucibacillary } \\
\text { (TT, BT) }\end{array}$} & \multicolumn{1}{c}{$\begin{array}{c}\text { Multibacillary } \\
\text { (BB, BL, LL) }\end{array}$} \\
\hline Daily self-administered & Dapsone $100 \mathrm{mg} / \mathrm{d}$ po & $\begin{array}{l}\text { Dapsone } 100 \mathrm{mg} / \mathrm{d} \text { po }+ \\
\text { Clofazimine } 50 \mathrm{mg} / \mathrm{d} \text { po }\end{array}$ \\
Intermittent supervised & Rifampicin $600 \mathrm{mg} / 4 \mathrm{wk}$ im & $\begin{array}{l}\text { Rifampicin } 600 \mathrm{mg} / 4 \mathrm{wk} \mathrm{im}+ \\
\text { Clofazimine } 300 \mathrm{mg} / 4 \mathrm{wk} \mathrm{im}\end{array}$ \\
Duration & For 6 months & For indefinite period \\
\hline
\end{tabular}

social circumstances) than the severity of disease (i.e. personal experience). ${ }^{43}$ The patient's 'sick role' is also defined: 'is the patient expected to continue work?, to socialize?'.

\section{F Design of intervention trials}

Before trying manoeuvres to improve the situation, reliable treatment trials should establish efficacy of the regime and the endpoint or therapeutic goal for compliance, and surveys should identify the main source of difficulty and suggest relevant intervention methods. The manoeuvre should be isolated from other variables, especially the amount of time doctor spends with patient (a most effective placebo), with appropriate control groups. A representative sample of the treatment population should be randomized into trial and control groups, and stratified according to known factors affecting compliance ${ }^{22}$ or described demographically after randomization (for a good example, see ref ${ }^{44 .}{ }^{45}$ ). Both benefits and 'side-effects' should be reported-health education may make some patients more reliable, while increasing the demand for treatment and terrifying the rest of the population (see Figure 2).

The question must be asked if the result is just 'striving officiously', doing more harm than good to the patient, ${ }^{56}$ or violating Mill's dictum as applied to public health: 'the only purpose for which power can rightfully be exercised over any member of a civilized community against his will is to prevent harm to others. ${ }^{57}$

Since Kinnear Brown's work in Uganda in the 1930's, and T F Davey's in East Nigeria in the 1940 's, the value of peripheral treatment centres for leprosy has been recognized. ${ }^{37}$ With dispensing devolved onto semi-skilled workers (and former patients) and attractive clinics, the emphasis was placed on community involvement and morale. The use made of modern treatment outposts is often disappointing, ${ }^{15}$ perhaps permanent, established, well-run clinics, requiring time and effort to

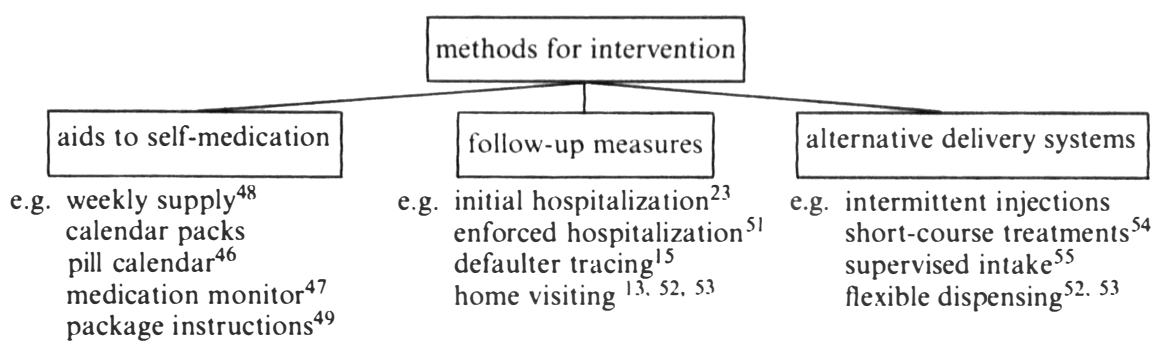

package instructions

education classes ${ }^{44}$

behavioural engineering ${ }^{50}$

Figure 2. Some methods for intervention in drug treatments. 
obtain treatment, seen to regard the disease seriously, and impressing prognosis on the patient from the outset, would be psychologically more effective.

\section{G Proposals for improving compliance}

\section{(i) TEACHING}

Doctors are teachers (Lat. 'docere'), but before they teach others, they need to be taught. As Samuel Butler would say, 'He that complies against his will, is of his own opinion still'. ${ }^{58}$

Doctors must listen to their patients', and treatment systems require feedback of patient concerns. ${ }^{59}$ Individually, the patient in hospital can be instructed on the regime and allowed to practise self-administration under observation before discharge. ${ }^{41}$ With family and friends present, a 'therapeutic contract' can be negotiated and participation encouraged. ${ }^{60}$ In the community, advertising such as Ryrie used in Malaysia, ${ }^{61}$ and re-establishment of traditional community leaders' and healers' involvement in treatment, can encourage trust and social acceptance.

\section{(ii) CO-OPERATION}

The continued devolution of responsibility for dispensing to field workers must continue, ${ }^{62}$ concentrating on: strategic location of dispensing points such as at workplaces, ${ }^{63}$ emphasizing continuous care and encouraging feedback; and closer communication between doctors and drug suppliers. ${ }^{64}$ Compliance is not just the patient's problem-doctor compliance to matters of policy ${ }^{65}$ and drug availability through rural distribution systems ${ }^{18}$ are at least as important challenges.

\section{(iii) SUSPICION}

Few doctors overestimate compliance. ${ }^{25} \mathrm{~A}$ high index of suspicion of non-compliance, within sensible ethical limits, must be held to a patient not getting better on a proven drug treatment. Simple manoeuvres such as pill-counting or regular questioning, or even subtle urine tests, must be considered within economic limits.

\section{(iv) TREATMENT}

'When a lot of remedies are suggested for a disease, that means it can't be cured'. ${ }^{66}$ The WHO-recommended regimens (Table 3 ) should be uniformly applied. Combination tablets should be produced to simplify the regimen-compliance advantages ${ }^{34}$ out weigh difficulties or contraindications and side-effects. ${ }^{67}$ More drastic measures, such as compulsory detention, ${ }^{51}$ use of psychotropic drugs, ${ }^{68}$ and abandonment of the hard-core unco-operative, ${ }^{69}$ illustrate the seriousness of the problem, but are of historical interest only.

\section{H Conclusions}

We have seen how a historical perspective, a definition of problems and possible solutions, and an analysis of past research can direct and guide efforts to regain the momentum of reducing the incidence and morbidity of chronic diseases such as leprosy. Perhaps the largest discovered need is for better quality research, to understand and logically tackle individual situations. A sound protocol for studies of dapsone compliance has been recently described. ${ }^{17}$ 
The future must be seen with hard economic spectacles. The WHO aims - for chemotherapy, to interrupt the chain of transmission and avoid permanent disabilities ${ }^{8}$-are economically sound. The waste of non-compliance was the motivating force for original compliance research. The medical costs, in terms of retreatment and rehabilitation, as well as the social costs of manpower and exile, should be made plain to all.

As well as politicians and administrators, practitioners in the front-line must recognize the need and consider imaginatively alternative strategies. ${ }^{65}$ Edmund Burke wrote, after the French Revolution, 'Every politician ought to sacrifice to the graces, and to join compliance with reason' ${ }^{70}$ After the therapeutics revolution, physicians will doubtless need to also- to effect Naaman's cure tomorrow.

\section{Acknowledgments}

My thanks to Miss Judy Hocking BA for typing the manuscript, Dr Colin MacDougall for his encouragement, and my colleagues at 'Colled' for their patience with me.

\section{References}

12 Kings 5. 10-12 King James' Bible (ninth century BC).

2 Ackerknecht E. Natural diseases and rational treatment in primitive medicine. Bull Hist Med, 1946; 19: 467-97.

3 Ackerknecht E. Therapeutics from the primitives to the twentieth century. New York: Macmillan, 1973.

4 Gupta KNNS. The ayurvedic system of medicine. Chatterjee, 1909.

5 Robbins JA. Patient compliance. Primary care, 1980; 7: 703-11.

${ }^{6}$ Davey TF. Realism in leprosy control. Lepr Rev, 1974; 45: 197-200.

7 Browne SG. The clinical evaluation of drugs for leprosy. Trans Roy Soc Trop Med Hyg, 1967; 61: 601-6.

${ }^{8}$ Editorial. Chemotherapy of leprosy. Lancet, 1982; ii: 77-8.

${ }^{9}$ Waters MFR. Leprosy. In: Oxford Textbook of Medicine. Weatherall DJ et al. (ed), Oxford: OUP, 1983.

10 Brook RH et al. Effectiveness of inpatient follow-up care. NEJM, 1971; 285: 1509-14. .

"Greene, Graham. A burnt-out case. Harmondsworth; Penguin, 1963.

12 Hippocrates. Regimens in acute diseases. In: Chadwick J and Mann WN (transl) The Medical Works of Hippocrates. Oxford: OUP, 1950.

${ }^{13}$ Quoted in Fox W. The problem of self-administration of drugs-with particular reference to pulmonary tuberculosis. Tubercle, 1958; 39: 269-74.

14 Ellard GA et al. Urine tests to monitor the self-administration of dapsone by leprosy patients. Am J Trop Med Hyg, 1974; 23: 464-70.

15 Hertroijs AR. A study of some factors affecting the attendance of patients in a leprosy control scheme. Int J Lep, 1974; 42: 419-27.

16 Low SJM \& Pearson JMH. Do leprosy patients take dapsone regularly? Lepr Rev, 1974; 45: 218-23.

17 Ellard GA et al. The application of urine tests to monitor the regularity of dapsone self-administration. Lepr Rev, 1974; 45: 224-34.

18 Hagan KJ et al. The reliability of self-administration of dapsone of leprosy patients in Burma. Lepr Rev, 1979; 50: 201-11.

19 Ellard GA et al. The self-administration of dapsone by leprosy patients in Ethiopia. Lepr Rev, 1981; 52: 237-43. 
20 Kent PW et al. Comparison of results achieved in controlled clinical trials with those achieved by the routine treatment services. Tuhercle, 1970; 51: 24-38.

${ }^{21}$ Gordis L. Conceptual and methodological problems in measuring patient compliance. In: Compliance in health care, Haynes RB et al (ed), Baltimore: Johns Hopkins, 2nd ed. 1979.

${ }^{22}$ Sackett DW. Methods for compliance research. In: Haynes RB et al (ed) op cit.

${ }^{23}$ Research Ctte of TB Society of Scotland. A controlled trial of chemotherapy in pulmonary tuberculosis of doubtful activity. Tuhercle, 1958; 39: 129-37.

${ }^{24}$ Charney E et al. How well do patients take oral penicillin? A collaborative study in private practice. Pediatrics, 1967; 40: 188-95.

${ }^{25}$ Caron HS \& Roth HP. Patients' co-operation with a medical regimen. JAMA, 1968; 203: 120-6.

${ }^{26}$ Ellard GA et al. An evaluation of the potential use of INH for monitoring the self-administration of drugs. Brit J Clin Pharm, 1980; 10: 369-81.

27 Huikeshoven $\mathrm{H}$ et al. ELISA inhibition technique for the demonstration of sulphones in body fluids. Lepr Rev, 1981; 52: 215-20, 221-8.

${ }^{28}$ Porter AMW. Drug defaulting in a general practice. Br Med J, 1969; i: 218-22.

${ }^{29}$ Moulding $\mathrm{T}$ et al. Supervision of outpatient drug therapy with the medication monitor. Ann Int Med, 1970; 73: 559-64.

${ }^{30}$ Norrell SE. Malignant compliance. Lancet, 1982; i: 50.

${ }^{31}$ Blackwell B. Patient compliance. NEJM, 1973; 289: 249-51.

${ }^{32}$ Berry D et al. Tuberculous patients treated at home. Am Rev Resp Dis, 1963; 88: 769-72.

${ }^{33}$ Wilcocks C \& Manson-Bahr PEC (ed). Manson's tropical diseases. (Chapter 18). London: Balliere-Tyndell, 1972.

${ }^{34}$ Mazzullo J. The non-pharmacological basis of therapeutics. Clin Pharm Ther, 1972; 13: 157-8.

${ }_{35}$ Ridley. Leprous reversal reactions. Lepr Rev, 1969; 40: 77.

${ }^{36}$ Jonson, Ben. Volpone.

37 Feeny P. The fight against leprosy. London: Elek books, 1964.

${ }^{38}$ Becker MH et al. Patient perceptions and compliance - recent studies of the health belief model. In: Haynes RB et al (ed) op cit.

${ }^{39}$ Davis MS. Variations in patients' compliance with doctors' advice - an empirical analysis of patterns of communication. Am J Puhl Hth, 1968; 58: 274-88.

40 Ogunyema O. Reasons for failure of antihypertensive treatment. $\mathrm{Br}$ Med J, 1983; 286: 1956.

${ }^{41}$ Swinyard EA. Patient compliance instruction. In: Goodman \& Gilman's pharmacological basis of therapeutics. 6th ed. New York: Macmillan 1980.

${ }^{42}$ Waxler NE. Learning to be a leper: a case study in the social construction of illness. In: Mishler EG et al. Social contexts of health, illness and patient care. Cambridge: CUP, 1981.

${ }^{43}$ Haynes RB. Determinants of compliance-the disease and the mechanics of treatment. In: Haynes RB et al. (ed) op cit.

44 Sackett DL et al. Randomised clinical trial of strategies for improving medication compliance in primary hypertension. Lancet, 1975; i: 1205-7.

${ }^{45}$ Haynes R B et al. Improvement of medication compliance in uncontrolled hypertension. Lancet, 1976; i: $1265-8$.

46 Moulding TS. Preliminary study of the pill calendar as a method of improving the self-administration of drugs. Am Rev Resp Dis, 1961; 84: $284-7$.

${ }^{47}$ Moulding TS. The case for routine supervision of tuberculosis treatment with the medication monitor. Chest, 1981; 79: 377-8.

48 Mayer TC. Drug defaulting in general practice. Br Med J, 1969; i: 783.

${ }^{49}$ Morris LA \& Halperin JA. Effects of written drug information on patient knowledge and compliance-a literature review. Am J Publ Hth, 1979; 69: 47-52.

50 Azrin NH \& Powell J. Behavioural engineering-the use of response priming to improve prescribed self-medication. J App Behav Anal, 1969; 2: 39-42. 
51 Mikkelson MK et al. Ambulatory ТB Chemotherapy on an Indian reservation. Chest, 1973; 64: 57()-73.

52 WHO centre for TB chemotherapy, Praguc. A study of two twice-weekly and one once-weckly continuation regimens, including a comparison of two durations of treatment. Tubercle, 1976; 57: 235-49.

53 Moodie AS. Mass ambulatory chemotherapy in the treatment of tuberculosis in a predominantly urban community. Am Rev Resp Dis, 1967; 95: 384-97.

54 Aquinas M. Short-course chemotherapy for tuberculosis. Drugs, 1982; 24: 118-32.

55 Poole G and Stradling P. Intermittent chemotherapy for TB in an urban community. Br Med J, 1969; i: $82-4$.

56 Simpson JMD. Simple tests for the detection of urinary PAS. Tuhercle, 1956; 37: 333-40.

57 Mill, John Stuart. On liherty. (1859).

58 Butler, Samuel. Hudihras. (1663).

59 Finnerty FA et al. Hypertension in the inner city-analysis of clinical dropouts. Circulation, 1973; 47: 73-5.

60) Litman TJ. The family in health and health care-a socio-behavioural overview. In: Patients, physicians and illness. Jaco EG (ed), New York: Free Press, 1979.

61 Ryrie GA. Administering justice in a leper hospital. Lepr Rev, 1937.

62 Werner D. Where there is no doctor. 2nd ed. London: Macmillan, 1979.

${ }^{63}$ Kay DT. The treatment of pulmonary tuberculosis at work - a controlled trial. Tuhercle, 1957; 38: $375-81$.

${ }^{64}$ McKenney JM et al. The effect of clinical pharmacy services on patients with essential hypertension. Circulation, 1973; 48: 1104-11.

${ }^{65}$ Fox W. Compliance of patients and physicians - experience and lessons from tuberculosis. $\mathrm{Br}$ Med J, 1983; 287: 33-5, 101-5.

to Chekhov, Anton. Br Med J, The Cherry Orchard. (1903)

67 Rogers HJ et al. Compliance in introduction of new drugs. In: A texthook of clinical pharmacology. London: Hodder \& Stoughton, 1981.

6x Neves Almeida F. On the reasons for irregular self-administration of PAS. Tubercle, 1962; 43: $367-74$.

69 Luntz GRWN et al. Report on the use of 'phenistix' and the problems of long-term chemotherapy for tuberculosis. Br Med J, 1960; ii, 1679.

${ }^{70}$ Burke, Edmund. Reflections on the revolution in France. (1790). 